\title{
Commentary on Sclerotherapy of Telangiectasias: A Two-Step, Painless Technique
}

\author{
Martino Neumann, MD*
}

The author has indicated no significant interest with commercial supporters.

I $\mathrm{n}$ this issue, Philippe Kern ${ }^{1}$ describes a method for treating leg telangiectasia. The aim of this study was to investigate a possible method for pain reduction. Leg telangiectasias are a common problem in dermatologic surgical practice. Because of a lack of randomized controlled trials, most literature reports are restricted to a personal approach. $^{2,3}$ From dermato-phlebologic ${ }^{3}$ and cosmetic ${ }^{4}$ points of view, sclerotherapy is regarded as the first treatment option. There is much discussion about the place of lasers, ${ }^{5}$ but treatment of leg telangiectasias is a challenge. Side effects such as hyperpigmentation and small but resistant ulcers are more frequent than perhaps reported. In addition, treatment failures and recurrences are not uncommon.

It is a clinical observation that retreatment for recurrences becomes more difficult than the initial treatment. Kern has chosen an adequate approach to the treatment problem. He proposes first to treat the feeder reticular vein. For this he compared two techniques. The first technique is an injection at the most distal aspect of the feeder vein and, in a subsequent visit, an injection in the remaining telangiectasia, and the second technique is an injection in each side branch of the feeding reticular vein and telangiectasia at the same time. The effectiveness is the same, but pain is significantly less using the two-step method.
Unfortunately, he uses chromated glycerin as a sclerosing solution. This sclerosant is mainly used in France and some parts of Switzerland. Sclerotherapy pain sensation is different for each sclerosing agent. Hypertonic saline is the most painful and polidocanol the least painful. Chromated glycerin is said to cause more pain than polidocanol, so translation of this technique to extensive use of polidocanol is impossible. The use of epinephrine, added to the chromated glycerin, seems to be confounding. It will induce vasospasm, although the author did not observe vasospasm.

The most interesting aspect of the two-step treatment that the author proposes is the large number of injections. There is no significant difference between the techniques in numbers of injection. Because the amount of sclerosing solution injected should be just enough to fill the target vein, the volume per injection is automatically reduced with the number of injections per area. Pain reduction for a mostly cosmetic treatment will increase patient satisfaction, which measured the authors did not measure. It will be of great interest to compare the low-volume/high-injection technique with the approach in which the injected volume is based on the maximum filling of a certain vessel. $^{2,3}$

\footnotetext{
*Department of Dermatology, Erasmus University Hospital Rotterdam, Rotterdam, The Netherlands 


\section{References}

1. Kern P. Sclerotherapy of telangiectasias: a two step painless technique. Dermatol Surg 2012;38:860-4.

2. Neumann HA, Kockaert MA. The treatment of leg telangiectasia. J Cosmet Dermatol 2003;2(2):73-81.

3. Goldman MP. My sclerotherapy technique for telangiectasia and reticular veins. Dermatol Surg 2010;36:1040-5.

4. Vitale-Lewis VA. Aethetic treatment of leg veins. Aesthet Surg J 2008;28(5):573-83.
5. Silapunt S. Lasers and leg veins ... the saga to be continued. Dermatol Surg 2011;37:742-3.

Address correspondence and reprint requests to: Martino Neumann, MD, Department of Dermatology, Erasmus University Hospital Rotterdam, Burg. s' Jacobplein 51, 3015 CA Rotterdam, The Netherlands, or e-mail: h.neumann@erasmusmc.nl 